\title{
Pengaruh Pemberitaan Surat Kabar Kompas, Seputar Indonesia dan Media Indonesia Terhadap Persepsi Masyarakat Pengguna Tabung Gas
}

\author{
Arief Fajar \\ Program Studi Ilmu Komunikasi, FKI, Universitas Muhammadiyah Surakarta
}

\author{
Dwi Yunita Restivia \\ Alumni Program Studi Ilmu Komunikasi, FKI, Universitas Muhammadiyah \\ Surakarta
}

\begin{abstract}
Formulation and objectives of this research are: (1) describe the influence of newspaper reporting on the perceptions of users housewife gas cylinders in the RW 003 Margajaya Bekasi; (2) how much influence newspaper coverage of the perception of the housewife users of gas cylinders in the RW 003 Margajaya Bekasi. Referring to the results of the study, it can be concluded (1) reporting of newspaper has a significant influence in a positive direction toward the perception of the housewife users of gas cylinders in the RW 003 Margajaya South Bekasi; (2) newspaper news affect the perception of the housewife users of gas cylinders by $59 \%$. This means, whenever there is increase in newspaper coverage, then the resulting perception of the user housewife who use gas cylinders getting better.
\end{abstract}

Keywords: report of newspaper and the perceptions public of users gas cylinders

\section{Pendahuluan}

Seiring dengan program pemerintah dalam upaya mengurangi konsumsi minyak tanah ke gas, masyarakat dituntut beralih bahan bakar dari minyak ke gas. Dengan mengurangi subsidi untuk minyak tanah, sehingga menyebabkan harga minyak tanah semakin tinggi, serta masyarakat beralih menggunakan gas untuk memenuhi kebutuhan rumah tangga. Pemerintah dapat menghemat subsidi hingga Rp. 15-Rp. 20 triliyun jika program ini berhasil.

Namun, kebijakan tersebut menimbulkan masalah baru bagi masyarakat. Cara penggunaan yang belum dipahami secara jelas oleh masyarakat dan ditambah masalah kebocoran gas yang sering terjadi, sehingga menyebabkan tabung gas meledak. Munculnya kasus ledakan tabung gas LPG akibat kebocoran di selang dan regulator tabung gas, mendorong Badan Standarisasi Nasional (BSN) melakukan survei dan kajian penggunaan Standar Nasional Indonesia (SNI) pada produk tersebut. Ada lima hal yang terkait dengan tabung gas LPG, yaitu; kompor gas LPG, tabung baja LPG, katup tabung baja LPG, regulator dan 
selang karet. ${ }^{1}$

Berdasarkan hasil penelitian pada tahun 2009 oleh BSN, ditemukan hampir 100 persen selang tidak memiliki SNI, 66 persen katup tabung tidak memiliki SNI, 50 persen kompor gas tidak memiliki SNI, 20 persen regulator tidak memiliki SNI, dan hanya 7 persen tabung gas yang tidak memiliki SNI. Hal ini membuktikan masalah-masalah yang terjadi sampai saat ini. ${ }^{2}$

Peristiwa mengenai meledaknya tabung gas LPG juga tidak luput dari perhatian surat kabar, terutama bulan April-Mei 2010. Selama bulan April-Mei 2010 sudah terjadi 9 kejadian tabung gas LPG meledak dengan jumlah korban meninggal 9 orang di wilayah Jabodetabek. Diantaranya terjadi di Bekasi Utara pada tanggal 1 Mei 2010 dengan 1 orang luka bakar. ${ }^{3}$

Adanya peristiwa yang terjadi berulang dalam waktu yang berdekatan sering sekali diekspos oleh media massa baik media cetak maupun elektronik, sehingga beritanya tersebar luas di kalangan masyarakat. Media massa mempunyai pengaruh yang sangat besar terhadap persepsi yang dapat terbentuk di pikiran khalayak umum. Media komunikasi massa dapat dan memang telah mempengaruhi perubahan, apalagi jika itu menyangkut kepentingan orang banyak. Media juga mampu menggalang persatuan dan opini publik terhadap peristiwa tertentu. ${ }^{4}$

\footnotetext{
Lihat tulisan Rapat Dengar Pendapat Komisi VI DPR RI, 2010, www.bsn.go.id, diakses pada hari Minggu tanggal 20 Juni 2010 pukul 14.00.

Ibid.

Lihat Korban Gas Terus Bertambah, 2010, Kompas, edisi 29 Mei 2010.

4 Lihat William Rivers, 2004, Media Massa dan
}

Peristiwa ledakan tabung gas yang diberitakan oleh media (khususnya surat kabar) akan menimbulkan kekhawatiran bagi masyarakat terutama pengguna tabung gas LPG. Sebab, beberapa peristiwa meledaknya tabung gas LPG yang terjadi di Bekasi akan menjadi perhatian warganya. Bahkan didukung dengan pemberitaan surat kabar yang memberitakan dengan sangat detail. Bekasi sendiri merupakan salah satu sasaran pertama pemerintah dalam program konversi minyak tanah ke gas yang memiliki kepadatan penduduk yang cukup tinggi, serta dilihat dari karakteristik masyarakat Bekasi yang cenderung individual. Sehingga, pemberitaan tersebut akan mempengaruhi persepsi yang terbentuk di benak masyarakat.

Oleh karena itu, pemberitaan tersebut akan menimbulkan persepsi yang berbeda dari masyarakat khususnya warga RW 003 Margajaya Bekasi Selatan yang menggunakan tabung gas di rumahnya. Apalagi didukung dengan media surat kabar yang dominan digunakan warganya, yakni Kompas, Seputar Indonesia dan Media Indonesia yang merupakan surat kabar nasional.

Berdasarkan latar belakang tersebut, maka rumusan masalah dalam penelitian ini adalah (1) Bagaimana pengaruh pemberitaan surat kabar Kompas, Seputar Indonesia, dan Media Indonesia terhadap persepsi ibu rumah tangga pengguna tabung gas di RW 003 Margajaya Bekasi (terkait pemberitaan seputar meledaknya tabung gas)? dan (2) Seberapa besar pengaruh pemberitaan surat kabar

\footnotetext{
Masyarakat Modern, hal. 41.
} 
Kompas, Seputar Indonesia, dan Media Indonesia terhadap persepsi ibu rumah tangga pengguna tabung gas di RW 003 Margajaya Bekasi (terkait pemberitaan seputar meledaknya tabung gas)?

Tujuan dari dilakukannya penelitian ini adalah untuk mengetahui (1) pengaruh pemberitaan surat kabar Kompas, Seputar Indonesia, dan Media Indonesia terhadap persepsi ibu rumah tangga pengguna tabung gas di RW 003 Margajaya Bekasi (terkait pemberitaan seputar meledaknya tabung gas) (2) seberapa besar pengaruh pemberitaan surat kabar Kompas, Seputar Indonesia, dan Media Indonesia terhadap persepsi ibu rumah tangga pengguna tabung gas di RW 003 Margajaya Bekasi (terkait pemberitaan seputar meledaknya tabung gas)

\section{Komunikasi Massa}

Severin dan Tankard mendefinisikan komunikasi massa merupakan komunikasi yang diarahkan kepada audiens yang relatif besar, heterogen, dan anonim. Pesan-pesan yang disebarkan secara umum, sering dijadwalkan untuk bisa mencapai sebanyak mungkin anggota audiens secara serempak dan sifatnya sementara, serta komunikatornya yang cenderung berada dalam sebuah organisasi yang kompleks yang mungkin membutuhkan biaya yang besar. ${ }^{5}$

Dominick dalam Ardianto ${ }^{6}$ mengemukakan fungsi komunikasi massa adalah:

1. Pengawasan (Surveillance)

Lihat Werner J. Severin, 2005, Teori Komunikasi: Sejarah, Metode, dan Terapan di Dalam Media Massa, hal. 4.

6 Lihat Elnivaro Ardianto, 2005, Komunikasi Massa: Suatu Pengantar, hal. 16.
Fungsi pengawasankomunikasi massa dibagi dalam bentuk pengawasan peringatan dan pengawasan instrumental. Pengawasan peringatan terjadi ketika media massa menginformasikan tentang ancaman dari angin topan, meletusnya gunung merapi, kondisi efek yang memprihatinkan, tayangan inflasi atau adanya serangan militer. Sedang fungsi pengawasan instrumental adalah penyampaian atau penyebaran informasi yang memiliki kegunaan atau dapat membantu khalayak dalam kehidupan sehari-hari.

2. Penafsiran (Interpretation)

Media massa tidak hanya memasok fakta dan data, tetapi juga memberikan penafsiran terhadap kejadian-kejadian penting. Organisasi atau industri media memilih dan memutuskan peristiwa-peristiwa yang dimuat atau ditayangkan.

Tujuan penafsiran media ingin mengajak para pembaca atau pemirsa untuk memperluas wawasan dan membahasnya lebih lanjut dalam komunikasi antarpersona atau kelompok.

3. Keterkaitan (Linkage)

Media massa dapat menyatukan anggota masyarakat yang beragam, sehingga membentuk keterkaitan berdasarkan kepentingan dan minat yang sama tentang sesuatu.

4. Penyebaran Nilai (Transmission of Values)

Fungsi ini juga disebut sosialisasi. Media massa yang mewakili gambaran masyarakat itu ditonton, didengar, dan dibaca. Media massa 
memperlihatkan kepada kita bagaimana mereka bertindak dan apa yang diharapkan mereka.

5. Hiburan (Entertainment)

Melalui berbagai macam program acara yang ditayangkan televisi, khalayak dapat memperoleh hiburan yang dikehendakinya. Melalui berbagai macam acara di radio siaran pun masyarakat dapat menikmati hiburan. Sementara surat kabar dapat melakukan hal tersebut dengan memuat cerpen, komik, TTS, dan berita yang mengandung human interest (sentuhan manusiawi).

\section{Surat Kabar dan Berita}

Surat kabaradalah media komunikasi massa yang diterbitkan secara berkala dan bersenyawa dengan kemajuan teknologi pada masanya dalam menyajikan tulisan berupa berita, feature, pendapat, cerita rekaan (fiksi), dan bentuk karangan yang lain. Tujuan dasar dari surat kabar adalah memperoleh berita dari sumber yang tepat untuk disampaikan secepat dan selengkap mungkin kepada para pembacanya. ${ }^{7}$

Bleyer dalam Sumadiria mendefinisikan berita adalah sesuatu yang termasa yang dipilih oleh wartawan untuk dimuat dalam surat kabar, karena dia menarik minat atau mempunyai makna bagi pembaca surat kabar, atau karena dia dapat menarik para pembaca untuk membaca berita tersebut. ${ }^{8}$

Untuk menyajikan berita yang bernilai tinggi dan dapat merangsang

7 Lihat Ensiklopedi Nasional Indonesia Jilid 15, hal. 431.

8 Lihat AS Haris Sumadiria, 2005, Jurnalistik Indonesia: Menulis Berita dan Feature, hal. 64. bangkitnya perhatian orang banyak, ada empat faktor utama:

1. Kepentingan (Significance), yaitu kejadian yang berkemungkinan mempengaruhi kehidupan orang banyakatau kejadianyangmempunyai akibat terhadap kehidupan pembaca.

2. Besar (Magnitude), yaitu kejadian yang menyangkut angka-angka yang berarti bagi kehidupan orang banyak, atau kejadian yang berakibat yang bisa dijumlahkan dalam angka yang menarik buat pembaca.

3. Waktu (Timeliness), yaitu kejadian yang menyangkut hal-hal yang baru terjadi, atau baru dikemukakan.

4. Kedekatan (Proximity), yaitu kejadian yang dekat bagi pembaca. Kedekatan ini bisa bersifat geografis maupun emosional. ${ }^{9}$

\section{Persepsi}

Persepsi adalah inti komunikasi ${ }^{10}$ dan interaksi ${ }^{11}$. Persepsi disebut inti komunikasi, karena jika persepsi seseorang tidak akurat, tidak mungkin berkomunikasi dengan efektif. Persepsilah yang menentukan seseorang memilih suatu pesan dan mengabaikan pesan yang lain. Proses persepsi dibagi menjadi tiga aspek persepsi, yaitu penyeleksian, pengorganisasian, dan penginterpretasian dari rangsangan. ${ }^{12}$

\section{Perceptual Selection}

Kita melakukan seleksi hanya pada

9 Lihat Ashadi Siregar, 2004, Bagaimana Meliput dan Menulis Berita Untuk Media Massa, hal. 27.

10 Lihat Deddy Mulyana, 2005, IImu Komunikasi Suatu Pengantar, hal. 167.

11 Lihat Nunung Prajarto, 2010, Psikologi Komunikasi, hal. 1.

12 Lihat Loc.cit., hal. 169. 
karakteristik tertentu dari objek-objek persepsi kita dan mengabaikan yang lain. ${ }^{13}$ Menurut Schiffman dan Lazar ${ }^{14}$, ada empat konsep yang menjadi perhatian penting dari persepsi selektif yaitu:

I. Selective exposure, yaitu pencarian pesan yang sesuai dengan kondisi mereka saat itu.

II. Selective Attention, yaitu perhatian terhadap kejadian atau rangsangan, dimana masyarakat mempunyai kesadaran yang tinggi terhadap stimuli yang sesuai dengan kebutuhan dan ketertarikan mereka.

Menurut Mulyana 15 perhatian dipengaruhi oleh faktor-faktor berikut ini:
a. Gerakan
b. Ukuran dan intensitas stimuli
c. Kontras
d. Kebaruan
e. Perulangan

III. Perceptual Defense, yaitu penyaringan stimuli yang dianggap mengancam diri mereka.

IV. Perceptual Blocking, yaitu perlindungan diri setiap manusia dari serangan stimuli melalui pembatas yang dibentuk dari kesadaran (psikologis).

\section{Hipotesis}

Berawal dari permasalahan yang ada, maka hipotesis yang diajukan ialah: diduga bahwa pemberitaan surat kabar Kompas, Seputar Indonesia, dan Media

13 Lihat Marhaeni Fajar, 2009, Ilmu Komunikasi: Teori dan Pratek, hal. 151.

14 Lihat Lean G. Schiffman dan Leslie, 2000, Consumer Behavior, $7^{\text {st }}$ Ed. hal. 131.

15 Lihat Deddy Mulyana, 2005, Ilmu Komunikasi: Suatu Pengantar, hal. 183.
Indonesia mengenai meledaknya tabung gas berpengaruh terhadap persepsi masyarakat pengguna tabung gas di RW 003 Margajaya Bekasi Selatan.

\section{Metode Penelitian}

\section{Pendekatan Penelitian}

Pendekatan penelitian ini merupakan penelitian kuantitatif eksplanatif. Hubungan variabel dalam penelitian adalah hubungan kausal, yaitu hubungan yang bersifat sebab akibat. Ada variabel independen (pemberitaan surat kabar) dan variabel dependen (persepsi).

\section{Tempat dan Waktu Penelitian}

Adapun yang menjadi tempat penelitian adalah RW 003 Margajaya, Bekasi Selatan yang terletak di tengahtengah Kota Bekasi. Waktu penelitian akan dilaksanakan antara bulan JuniNovember 2010. Sedangkan, penelitian langsung di lapangan akan dilaksanakan antara bulan Juli-Agustus 2010.

\section{Populasi, Sampel dan Sampling}

\section{Populasi}

Populasi dalam penelitian ini adalah warga perempuan RW 003 (terbagi menjadi 5 RT) Margajaya Bekasi Selatan yang menggunakan tabung gas LPG yaitu 1346 orang.

\section{Sampel dan Teknik Pengambilan Sampel}

Sampel yang digunakan sebanyak 310 responden yaitu dengan rumus Solvin;

$\mathrm{N}=1346$ orang 


$$
\begin{aligned}
\mathrm{e} & =0,05 \\
\mathrm{n} & =\frac{1346}{1+1346(0,05)^{2}} \\
& =310
\end{aligned}
$$

\section{Sampel RT}

Pengambilan sampel tiap RT berdasarkan strata tidak proporsional. Maka setiap RT (5 RT) diambil sampel sebanyak $20 \%$ dari jumlah keseluruhan sampel, yaitu sebanyak 62 orang per RT.

\section{Sampel individu dari setiap RT}

Pengambilan unit sampel tiap RT digunakan teknik purposive sampling, dengan kriteria diantaranya:

1. Ibu rumah tangga pengguna tabung gas LPG

2. Ibu rumah tangga yang pernah membaca berita mengenai meledaknya tabung gas di surat kabar Kompas, Seputar Indonesia, dan Media Indonesia

\section{Definisi Konseptual}

a. Variabel Independen (X): Pemberitaan Surat Kabar

b. Variabel Dependen (Y): Persepsi Masyarakat Pengguna Tabung Gas

\section{Definisi Operasional}

Untuk menguji hipotesis dan mengukur variabel yang digunakan dalam penelitian ini, sekaligus menghindari terjadinya kesalahpahaman atau perbedaan pandangan, maka diberikan definisi operasional sebagai berikut.

a. Variabel independen (Pemberitaan Surat Kabar)
Pemberitaan surat kabar yaitu sesuatu yang menarik perhatian sejumlah khalayak yang dipublikasikan melalui media cetak surat kabar, dengan indikator:

1. Ketepatan waktu

2. Kedekatan tempat

3. Besarnya

4. Kepentingan

b. Variabel dependen (Persepsi)

Persepsi yaitu suatu proses dimana kita sadar akan banyaknya stimulus yang mempengaruhi indra kita. Persepsilah yang menentukan kita memilih suatu pesan dan mengabaikan pesan yang lain, dengan indikator:

1. Selective Exposure,

2. Selective Attention,

3. Perceptual Defense,

4. Perceptual Blocking

\section{Teknik Pengumpulan Data}

\section{Data Primer}

Sumber data primer ini adalah sumber data pertama dimana sebuah data dapat dihasilkan. Dalam penelitian ini data primer adalah hasil kuesioner yang dibagikan pada responden pengguna tabung gas yang pernah membaca surat kabar Kompas, Seputar Indonesia, dan Media Indonesia mengenai peristiwa meledaknya tabung gas dan responden tersebut harus ibu rumah tangga yang bertempat tinggal di RW 003 Margajaya Bekasi Selatan.

\section{Teknik Analisis Data}

Analisis Regresi Linier Sederhana 
Mengacu pada tujuan dan hipotesis penelitian, maka model analisis yang digunakan adalah analisis regresi linier sederhana. Dengan rumus sebagai berikut;

$\mathrm{Y}=\mathrm{a}+\mathrm{bX}$

Ket.

$\mathrm{Y}=$ variabel tidak bebas

$\mathrm{X}=$ variabel bebas

$\mathrm{a}=$ nilai intercept

$\mathrm{b}=$ koefisien arah regresi

\section{Koefisien Determinasi}

Analisis ini untuk mengetahui seberapa besar pengaruh variabel independen terhadap variabel dependen, yang ditunjukan dengan persentase;

Ket.

$$
R^{2}=\frac{b_{1} \Sigma X_{1} Y+b_{2} \Sigma X_{2} Y}{\Sigma Y^{2}}
$$

$\mathrm{R}^{2}=$ koefisien determinasi

$\mathrm{b} \quad=$ koefisien regresi

$X \quad$ variabel independen

$\mathrm{Y}$ = variabel dependen

Teknik analisis data yang digunakan adalah teknik analisis dengan memanfaatkan software SPSS (Statistical Product and Service Solution) version 16.00 for windows.

\section{Hasil Penelitian}

\section{Profil Responden}

Responden penelitian ini dipilih dari para ibu rumah tangga di RW 003 Margajaya Bekasi yang menggunakan tabung gas Elpiji sebanyak 310 responden yang dibagi ke dalam 5 RT, setiap RT dipilih 62 responden. Responden yang dipilih yaitu ibu rumah tangga yang menggunakan tabung gas Elpiji dan pernah membaca berita di surat kabar Kompas, Seputar Indonesia, dan Media Indonesia berkaitan dengan peristiwa meledaknya tabung gas LPG.

\section{Karateristik Responden Berdasarkan Umur}

Dalam penelitian ini responden berumur antara 30-40 tahun dengan persentase sebesar 43,54\%. Kemudian disusul 40-50 tahun sebesar 20,97\%, 30 tahun ke bawah dengan persentase $18,39 \%$ dan terakhir dengan persentase terkecil umur 50 tahun ke atas sebesar $17,10 \%$.

\section{Karakteristik Responden Berdasarkan Tingkat Pendidikan}

Tingkat pendidikan responden dalam penelitian ini pada jenjang SMA dengan persentase sebesar 67,74 \%. Disusul dengan tingkat pendidikan SMP sebesar 14,52 \%, kemudian SD dengan persentase 9,68 \% dan S1 sebesar 8,06\%.

\section{Temuan Penelitian}

\section{Data Pemberitaan Surat Kabar Kompas,} Seputar Indonesia, dan Media Indonesia

Skor rata-rata variabel pemberitaan surat kabar adalah sebesar 39,42 dengan nilai minimum sebesar 20 dan nilai maksimum sebesar 54. Nilai rata-rata variabel persepsi ibu rumah tangga pengguna tabung gas adalah sebesar 45,15 dengan nilai minimum sebesar 25 dan nilai maksimum sebesar 64 .

Sebagian besar pengaruh pemberitaan surat kabar Kompas, Seputar Indonesia, dan Media Indonesia berada dinilai antara 38-45 (50,97 \%) dan yang terendah adalah nilai antara 20-28 (9,03 
\%). Dalam penelitian ini, pemberitaan surat kabar berdasarkan jumlah data kuesioner jumlah skor totalnya adalah 12.219 atau jika dipersentasekan adalah 12.219:17.050x 100\% = 71,67 \%. Nilai 12.219 dalam kategori interval "tinggi". Sehingga adanya pemberitaan di surat kabar Kompas, Seputar Indonesia, dan Media Indonesia diharapkan dapat mempengaruhi persepsi ibu rumah tangga pengguna tabung gas.

Kriteria penilaian dalam penelitian ini menggunakan metode rating scale. Kriteria penilaian rating scale terbagi menjadi empat kriteria yaitu: sangat rendah, rendah, tinggi dan sangat tinggi. Adapun cara penentuannya adalah sebagai berikut:

a. Mencari jumlah skor kriterium kuesioner tertinggi. Dalam penelitian ini diperoleh jumlah skor kriterium tertinggi dari perkalian 5x11×310= 17.050. Angka 5 adalah nilai tertinggi butir jawaban kuesioner, 11 adalah jumlah pertanyaan dalam kuesioner (pervariabel) dan 310 adalah jumlah responden.

b. Membagi menjadi 4 bagian skala interval untuk penilaian yang disesuaikan dengan kriteria rating scale yaitu 17.050:4 = 3410. Angka ini untuk mengetahui jarak antara interval, sehingga terbagi menjadi empat bagian yaitu sebagai berikut.

Tabel 1.

Kriteria Penilaian Variabel Pemberitaan Surat Kabar

\begin{tabular}{|c|c|c|}
\hline No. & Jumlah Skor Total & Penafsiran \\
\hline 1. & $3410-6820$ & Sangat rendah \\
\hline 2. & $6821-10.230$ & Rendah \\
\hline 3. & $10.231-13.640$ & Tinggi \\
\hline 4. & $13.641-17.050$ & Sangat tinggi \\
\hline
\end{tabular}

\section{Persepsi Ibu Rumah Tangga}

Persepsi ibu rumah tangga RW 003 memiliki nilai antara 45-54 (45,49\%) dan yang terendah adalah ibu rumah tangga yang memiliki nilai antara 25-34 $(11,60 \%)$. Dalam penelitian ini persepsi ibu rumah tangga pengguna tabung gas berdasarkan jumlah data kuesioner jumlah skor totalnya adalah 13.996 atau jika dipersentasekan adalah 13.996:20.150 x $100 \%=69,46 \%$. Nilai 13.996 dalam kategori interval "tinggi". Hal ini menunjukkan bahwa persepsi ibu rumah tangga pengguna tabung gas tinggi. Kriteria penilaian menggunakan kriteria sebagai berikut; 
Tabel 2.

Kriteria Penilaian Variabel Persepsi Ibu Rumah Tangga

\begin{tabular}{|c|c|c|}
\hline No. & Jumlah Skor Total & Penafsiran \\
\hline 1. & $4030-8060$ & Sangat rendah \\
\hline 2. & $8061-12.090$ & Rendah \\
\hline 3. & $12.091-16.120$ & Tinggi \\
\hline 4. & $16.121-20.150$ & Sangat tinggi \\
\hline
\end{tabular}

\section{Pengujian Hipotesis}

\section{Analisis Regresi Linier Sederhana}

Hasil pengolahan data untuk regresi linier sederhana dengan menggunakan program SPSS 16.0 atau dapat disusun persamaan regresi linier sederhana sebagai berikut:

$$
Y=10,825+0,871 X_{1}
$$

Berdasarkan persamaan regresi linier sederhana di atas dapat diuraikan sebagai berikut:

a) Nilai konstanta bernilai positif sebesar 10,825, hal ini menunjukkan bahwa apabila variabel pemberitaan surat kabar Kompas, Seputar Indonesia, dan Media Indonesia konstan, maka persepsi ibu rumah tangga pengguna tabung gas akan positif.

b) Koefisien regresi variabel pemberitaan surat kabar Kompas, Seputar Indonesia, dan Media Indonesia $\left(\mathrm{b}_{1}\right)$ sebesar 0,871 bernilai positif, hal ini menunjukkan bahwa pemberitaan surat kabar Kompas, Seputar Indonesia, dan Media Indonesia mempunyai pengaruh positif terhadap persepsi ibu rumah tangga pengguna tabung gas. Artinya setiap ada peningkatan pemberitaan surat kabar, maka mengakibatkan persepsi ibu rumah tangga pengguna tabung gas semakin baik. c) t-tabel $=\mathrm{ta} / 2 ; \mathrm{n}-1$

$$
\begin{aligned}
& =0,05 / 2 ; 310-1 \\
& =0,025 ; 30 \\
& =1,960
\end{aligned}
$$

Ho diterima apabila -1,960 $\leq$ t-hitung $\leq 1,960$

Ho ditolak apabila t-hitung $>1,960$ atau t-hitung $<-1,960$

d) Berdasarkan hasil pengolahan data diperoleh nilai t-hitung sebesar 21,059. Oleh karena hasil uji t statistik (t-hitung) lebih besar dari nilai $t$ tabel $(21,059>1,960)$ atau Probabilitas $t$ lebih kecil dari 0,05 $(0,000<0,05)$ maka Ho ditolak pada taraf signifikansi 0,05. Artinya bahwa variabel pemberitaan surat kabar Kompas, Seputar Indonesia, dan Media Indonesia mempunyai pengaruh yang signifikan terhadap persepsi ibu rumah tangga pengguna tabung gas.

\section{Uji $\mathbf{R}^{2}$}

Hasil perhitungan untuk nilai $R^{2}$ dengan bantuan program SPSS, dalam analisis regresi sederhana diperoleh angka koefisien determinasi atau $\mathrm{R}^{2}$ sebesar 0,590. Hal ini berarti 59\% variasi perubahan persepsi ibu rumah tangga pengguna tabung gas dijelaskan oleh variasi perubahan faktor-faktor pemberitaan surat kabar Kompas, Seputar 
Indonesia, dan Media Indonesia. Sementara sisanya sebesar $41 \%$ diterangkan oleh faktor lain yang tidak ikut terobservasi.

\section{Pembahasan}

Pemberitaan Surat Kabar Kompas, Seputar Indonesia, dan Media Indonesia

Berdasarkan hasil analisis diketahui bahwa pemberitaan di surat kabar Kompas, Seputar Indonesia dan Media Indonesia pada subyek tergolong tinggi. Hal ini ditunjukkan oleh jumlah skor total pada variabel ini adalah 12.219. Ini berarti ketertarikan subyek penelitian pada pemberitaan di surat kabar Kompas, Seputar Indonesia, dan Media Indonesia mengenai meledaknya tabung gas LPG.

\section{Persepsi Ibu Rumah Tangga Pengguna Tabung Gas}

Persepsi ibu rumah tangga pengguna tabung gas pada subyek penelitian juga tergolong tinggi, ditunjukkan oleh jumlah skor total pada variabel ini adalah 13.996. Ini berarti subyek penelitian pada dasarnya memiliki persepsi yang positif terhadap penggunaan tabung gas dan ditambah dengan pemberitaan di surat kabar, menyebabkan objek penelitian menjadi lebih perhatian dan waspada.

\section{Pengaruh Pemberitaan Surat Kabar Terhadap Persepsi Ibu Rumah Tangga Pengguna Tabung Gas}

Hasil analisis data yang dilakukan terhadap pengaruh pemberitaan surat kabar Kompas, Seputar Indonesia, dan Media Indonesia terhadap persepsi ibu rumah tangga menyatakan pengaruh positif yang signifikan. Hal ini berarti setiap ada peningkatan pemberitaan surat kabar Kompas, Seputar Indonesia, dan Media Indonesia, maka mengakibatkan persepsi ibu rumah tangga pengguna tabung gas semakin baik.

Masyarakat Bekasi saat ini banyak yang menggunakan tabung gas untuk keperluan rumah tangganya. Mereka akan mempersepsikan secara berbeda dalam menanggapi berita terkait meledaknya tabung gas yang diberitakan di surat kabar Kompas, Seputar Indonesia, dan Media Indonesia. Karena berita yang ditampilkan di surat kabar ialah berita yang terbaru dan sesuatu yang baru biasanya selalu menarik perhatian publik. Berdasarkan hasil analisis diketahui besarnya sumbangan antara variabel pemberitaan surat kabar Kompas, Seputar Indonesia, dan Media Indonesia terhadap persepsi ibu rumah tangga pengguna tabung gas sebesar $59 \%$ yang ditunjukkan oleh koefisien determinasi $\left(\mathrm{r}^{2}\right)$ sebesar 0,59 . Hal ini berarti masih terdapat $41 \%$ faktor-faktor lain yang mempengaruhi persepsi ibu rumah tangga pengguna tabung gas di luar variabel pemberitaan surat kabar Kompas, Seputar Indonesia, dan Media Indonesia.

Berdasarkan hasil perhitungan diketahui bahwa pemberitaan surat kabar Kompas, Seputar Indonesia, dan Media Indonesia berpengaruh positif dan signifikan terhadap persepsi ibu rumah tangga. Ditunjukkan dengan diperoleh nilai korelasi (r) sebesar 0,768; $p=0,000$ di bawah 0,05 . Pengaruh positif menunjukkan bahwa semakin informatif berita yang disampaikan surat kabar Kompas, Seputar Indonesia, dan Media Indonesia akan semakin meningkatkan persepsi ibu rumah tangga dalam penggunaan tabung gas. Berarti, 
walaupun informasi tentang ledakan tabung gas mengkhawatirkan, namun ibu rumah tangga pengguna tabung gas di RW 003 Margajaya Bekasi mempunyai pikiran yang positif atas informasi tersebut sehingga cenderung antisipasi dengan mempelajari penggunaan tabung gas secara benar.

\section{Simpulan}

Berdasarkan hasil analisis data pada pembahasan sebelumnya dapat disimpulkan sebagai berikut:

1. Pemberitaan surat kabat Kompas, Seputar Indonesia, dan Media Indonesia berpengaruh positif dan signifikan terhadap persepsi ibu rumah tangga pengguna tabung gas. Pengaruh positif menunjukkan bahwa informasi ledakan tabung gas dari surat kabar Kompas, Seputar Indonesia, dan Media Indonesia direspon positif dengan mengantisipasi agar kejadian ledakan tabung gas dapat dihindari.

2. Hasil perhitungan koefisien determinasi atau diperoleh nilai $\mathrm{R}^{2}$ sebesar 0,590. Hal ini berarti $59 \%$ persepsi ibu rumah tangga pengguna tabung gas dipengaruhi oleh pemberitaan surat kabar Kompas, Seputar Indonesia, dan Media Indonesia. Sementara sisanya sebesar $41 \%$ dipengaruhi oleh faktor lain yang tidak ikut terobservasi.

\section{Saran}

Berdasarkan hasil penelitian ini dapat diberikan saran akademis sebagai berikut :

1. Penelitian selanjutnya sebaiknya mengembangkan variabel-variabel yang diteliti antara lain pengalaman, lingkungan fisik, dan selektifitas, sebab tidak menutup kemungkinan bahwa dengan penelitian yang mencakup lebih banyak variabel akan dapat menghasilkan kesimpulan yang lebih baik.

2. Pemberitaan surat kabar Kompas, Seputar Indonesia, dan Media Indonesia berpengaruh signifikan terhadap persepsi ibu rumah tangga pengguna tabung gas. Oleh karena itu, variabel tersebut dapat dijadikan dasar untuk penelitian selanjutnya.

\section{Daftar Pustaka}

\section{Buku}

Anonim (1991). Ensiklopedi Nasional Indonesia Jilid 15. Jakarta, PT. Cipta Adi Pustaka

Ardianto, Elvinaro (2005). Komunikasi Massa: Suatu Pengantar. Bandung, Simbiosa Rekatama Media

Fajar, Marhaeni (2009). Ilmu Komunikasi: Teori dan Praktek. Yogyakarta, Graha Ilmu

Mulyana, Deddy (2005). Ilmu Komunikasi: Suatu Pengantar. Bandung, PT. Remaja Rosda Karya

Prajarto, Nunung (2010). Psikologi Komunikasi. Yogyakarta, Fisipol UGM

Rivers, William. dkk. (2004). Media Massa dan Masyarakat Modern. Jakarta, Prenada Media

Schiffman, Lean G. dan Leslie Lazar (2000). Consumer Behavior, $7^{\text {th }}$ Edition. NJ, Prentice-Hall.

Severin, Werner J dan James W. Tankard (1993). Communication Theories: Origins, Methods, EUses in the 
Mass Media. Penerjemah Sugeng Hariyanto. 2005. Teori Komunikasi: Sejarah, Metode, dan Terapan di Dalam Media Massa. Prenada Kencana: Jakarta.

Siregar, Ashadi (2004). Bagaimana Meliput dan Menulis Berita Untuk Media Massa. Yogyakarta, Penerbit Kanisius

Sumadiria, AS Haris (2005). Jurnalistik Indonesia: Menulis Berita dan Feature. Bandung, Simbiosa Rekatama Media

\section{Non Buku}

Korban Gas Terus Bertambah . 2010. Kompas. Edisi 29 Mei. Hal.1.

Rapat Dengar Pendapat Komisi VI DPR RI. 2010. www.bsn.go.id. Diakses pada hari Minggu tanggal 20 Juni 2010 pukul 14.00 WIB. 